\title{
Recent Advances in Screening and Treatment for Amblyopia
}

Eileen E. Birch · Krista R. Kelly · Jingyun Wang

Received: July 23, 2021 / Accepted: August 26, 2021 / Published online: September 9, 2021

(C) The Author(s) 2021

\begin{abstract}
Amblyopia is the most common cause of monocular visual impairment in children, with a prevalence of $2-3 \%$. Not only is visual acuity reduced in one eye but binocular vision is affected, fellow eye deficits may be present, eye-hand coordination and reading can be affected, and self-perception may be diminished. New technologies for preschool vision screening hold promise for accessible, early, and accurate detection of amblyopia. Together with recent advances in our theoretical understanding of amblyopia and technological advances in amblyopia treatment, we anticipate improved visual outcomes for children affected by this very common eye condition. This article is based on previously conducted studies and does not contain any new studies with human participants or animals performed by any of the authors.
\end{abstract}

\section{E. E. Birch $(\square) \cdot$ K. R. Kelly}

Retina Foundation of the Southwest, 9600 N.

Central Expressway, Suite 200, Dallas, TX 75231,

USA

e-mail: ebirch@retinafoundation.org

E. E. Birch · K. R. Kelly

Department of Ophthalmology, University of Texas

Southwestern Medical Center, Dallas, TX, USA

J. Wang

SUNY College of Optometry, State University of

New York, New York, NY, USA
Keywords: Amblyopia; Binocular vision; Children; Suppression; Treatment; Vision screening

\section{Key Summary Points}

Amblyopia is the most common cause of monocular visual acuity impairment in children, affecting 2 or 3 of every 100 children, but is treatable if detected early.

Pediatricians report that the high false positive rate of automated tests that screen for risk factors is a major barrier to preschool vision screening, leading to a lack of confidence in results and a reduced likelihood that they will refer a child for eye care on the basis of a screening failure.

New screening technologies (binocular retinal birefringence, optokinetic nystagmus (OKN) visual acuity, artificial intelligence) directly target amblyopia, not risk factors, and hold promise in providing more accurate preschool screening.

Recent technological advances in amblyopia treatment provide alternatives that can be used alone or in combination with standard-of-care treatments (patching, atropine, and Bangerter filters), with the potential to improve compliance and vision outcomes. 


\section{INTRODUCTION}

Amblyopia is a disorder of neurodevelopment that results from inadequate visual experience during the first years of life. It is the most common cause of monocular visual acuity impairment in children, affecting 2 or 3 of every 100 children [1-3]. Appropriate visual stimulation, including clear retinal images in each eye and proper ocular alignment are needed for normal visual development. Anisometropia and strabismus are two common pediatric eye conditions that can interfere with visual stimulation during development, placing children under 7 years of age at risk for amblyopia. It is widely appreciated that the success of amblyopia treatment declines with increasing age, and failure to detect and remediate it with early treatment can result in permanently decreased visual acuity in one eye. Here we review recent technological advances in early childhood screening and treatment for amblyopia that are providing hope for earlier detection and better outcomes.

\section{ADVANCES IN SCREENING FOR AMBLYOPIA}

Screening for amblyopia is recommended as a part of routine health surveillance for children aged 3-5 years in many countries [4-7]. Accurate screening methods that can be employed by pediatricians, family care practitioners, nurses, or community organizations could identify amblyopia at a time when treatment is most effective. Accurate screening can also reduce false positives, and spare nonamblyopic children the need for a complete eye exam, saving both time and health care resources. We know that repeated early vision screening improves vision outcomes. In a population-based, randomized longitudinal study, repeated early screening resulted in a $60 \%$ decreased prevalence of amblyopia and improved visual acuity outcome at age 7 years compared with surveillance only until school entry [8-10]. Moreover, amblyopia can be treated more effectively when treated early; the same study found a $70 \%$ lower prevalence of residual amblyopia after treatment when therapy was initiated before age 3 years [8-10].

The gold standard for amblyopia screening is visual acuity testing and most vision screening programs still rely on visual acuity charts as their primary screening test for amblyopia $[4-7,11]$. However, only one-third of 3-year-old and half of 4-year-old children can complete a visual acuity test of each eye [11-15]. Automated devices provide a simple, more successful approach to screening, aiming to detect refractive error and strabismus risk factors for amblyopia, rather than detecting amblyopia directly. However, the prevalence of risk factors is $21 \%$ compared to a prevalence of amblyopia of $2.5 \%$, i.e., 8 or 9 of every 10 children who fail automated screening because they have a risk factor are false positives and do not have amblyopia [16]. In a recent study of 10,000 3 -year-olds seen in the Pediatric Research in Office Settings (PROS) network, pediatricians reported not even attempting screening for $62 \%$ of children [12]. PROS members reported that the high false positive rate (over-referral) of automated screeners was the major barrier [12]. False positives lead to higher health care costs, parental anxiety, and a lack of confidence in screening results. Lack of confidence in turn leads to a reduced likelihood that the pediatrician will refer a child for eye care as a result of a failed screening exam, and a reduced likelihood that the family will seek eye care when referred. Because of the high false positive rate, the "earlier is better" notion has recently been called into question because automated screening may lead to unneeded office visits, treatment, financial burden, and potential psychosocial harm [17]. New alternatives for early vision screening that target amblyopia directly rather than risk factors are on the horizon, including retinal birefringence, optokinetic nystagmus visual acuity screening, and artificial intelligence.

\section{Binocular Retinal Birefringence Screening}

Recently, retinal birefringence scanning has been developed as a method to detect 
amblyopia and strabismus. Retinal birefringence scanning takes advantage of the unique architecture of the human fovea, with its radial organization of the Henle fibers. Because the Henle fiber layer is a birefringent tissue, a spot of polarized light scanned in an annulus at $100 \mathrm{~Hz}$ during central, steady foveal fixation will result in frequency doubling and $200 \mathrm{~Hz}$ will be the dominant signal frequency in the returning light. If fixation is unsteady or eccentric because of amblyopia, there will be little or no birefringence and, as a result, little or no $200 \mathrm{~Hz}$ signal in the returning light (Fig. 1). In a pair of studies, 400 preschool children were screened using a prototype retinal birefringence scanner that collected five scans in $2.5 \mathrm{~s}$ from children aged 2-6 years old at two pediatric ophthalmology private practices and at one pediatric primary care practice $[18,19]$. Screening results were compared with findings at a gold standard comprehensive examination by a pediatric ophthalmologist who was masked to screening results. Overall, binocular retinal birefringence scanning had 97\% sensitivity (ability to accurately detect amblyopia/ strabismus) and 90\% specificity (ability to correctly identify children without amblyopia), a significantly lower false positive rate than screening for risk factors. In 2016, binocular retinal birefringence scanning won US Food and Drug Administration (FDA) de novo clearance, with indications for screening young children for amblyopia and strabismus. After minor redesign, the device is now available as the bling ${ }^{\circledR}$ (Fig. 2).

\section{Optokinetic Nystagmus Visual Acuity Screening}

Because the gold standard for amblyopia screening is visual acuity testing, there is great interest in developing an objective measurement of visual acuity in young children. The Objective Acuity Vision Screener is currently under development to meet this need. Unlike optokinetic nystagmus (OKN) drums commonly used in the clinic, this test uses novel vanishing optotypes to induce involuntary OKN eye movements (Fig. 3) [20, 21]. While the high contrast black and white bars of the OKN

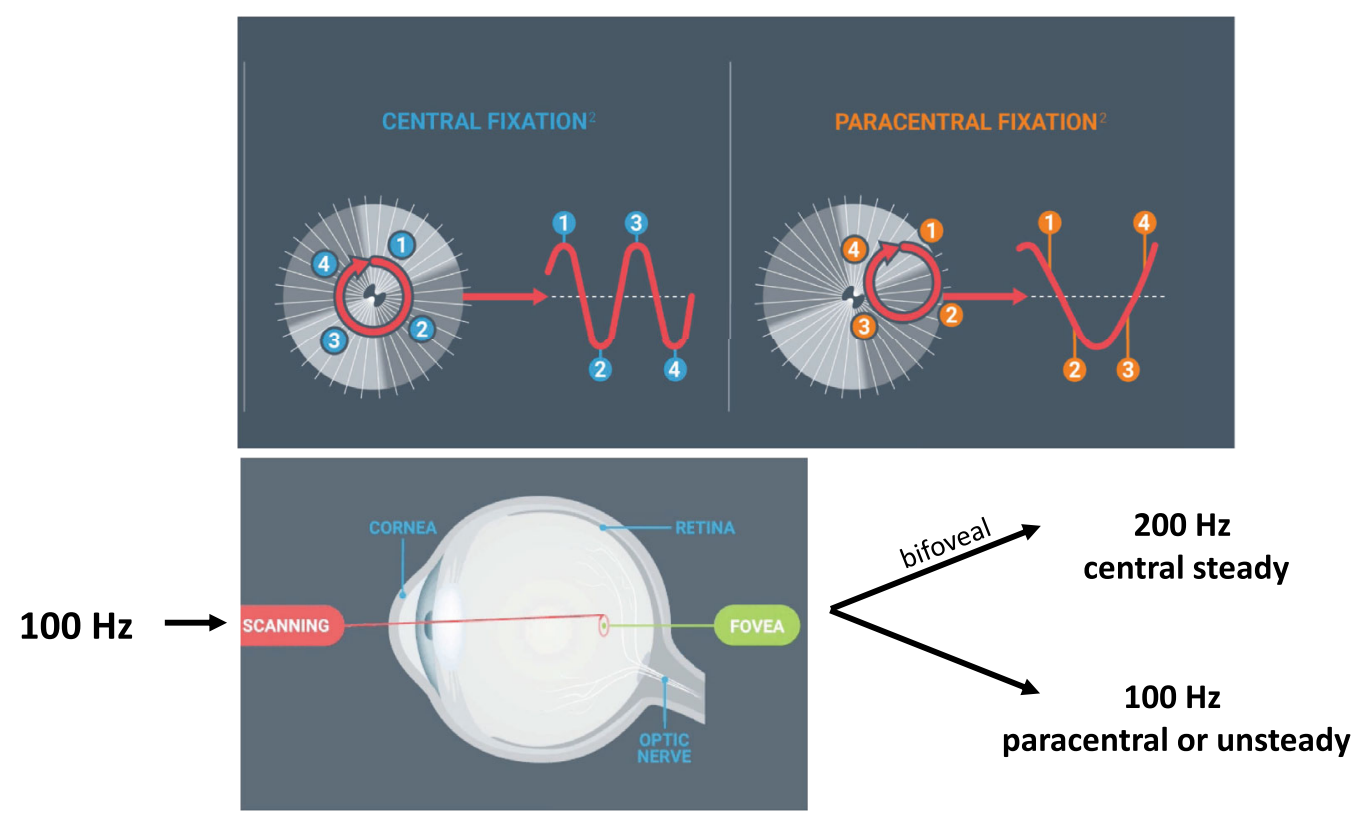

Fig. 1 Using retinal polarization scanning to measure bilateral fixation via Henle nerve fiber patterns that surround the fovea, the blinq ${ }^{\circledR}$ determines if faulty fixation is present and provides direct screening of microstrabismus as small as $1^{\circ}$ and amblyopia. Reprinted with permission from https://www.rebion.net 

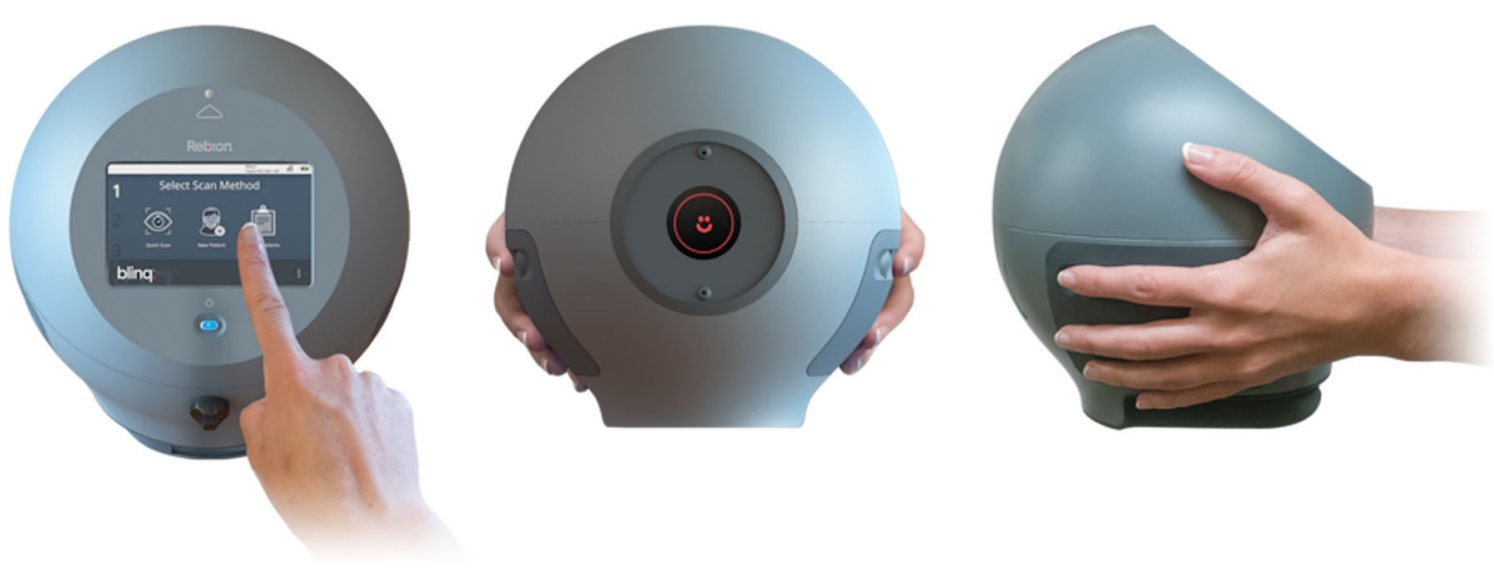

Fig. 2 The blinq ${ }^{\circledR}$ provides a definitive "pass" and “refer" output for amblyopia, including refractive amblyopia, microstrabismus, and strabismus. Reprinted with permission from https://www.rebion.net

drum used in the clinic are useful in determining whether a gross vision response is present, there is no clear relationship with visual acuity. On the other hand the vanishing optotypes used in the Objective Acuity Vision Screener are highly correlated with ETDRS visual acuity in adults [22].

Historically, the evaluation of eye movements has been limited because it requires (1) expensive recording equipment, (2) cooperative children able to hold a steady head position, and (3) expertise to interpret eye movement recordings. In the Objective Acuity Vision Screener, the first is overcome by presenting the visual stimuli on an inexpensive, portable iPad and collecting eye movement data via its internal camera; this platform also provides versatility needed for various screening settings and for field use in underserved areas [20, 21]. Second, the requirement for steady head position was solved by use of facial feature recognition software to measure and subtract motion of the head, allowing stabilization of the position of the eyes within the frame $[20,21]$. Third, the need for expertise was reduced by developing software to automatically detect presence or absence of OKN [20, 21] (Fig. 4). Ongoing clinical trials are evaluating the sensitivity and

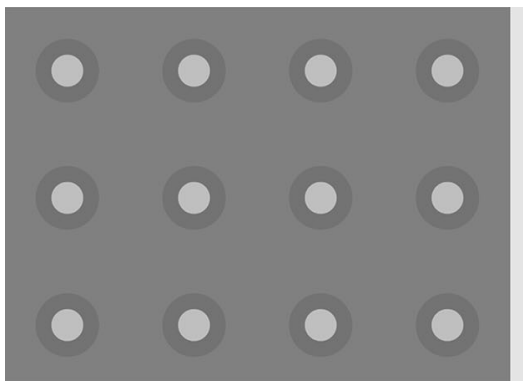

Fig. 3 Novel vanishing optotype that can elicit OKN when seen but vanishes into the background if the child's visual acuity is below age normal. For preschool vision screening, children are tested with vanishing optotype sizes
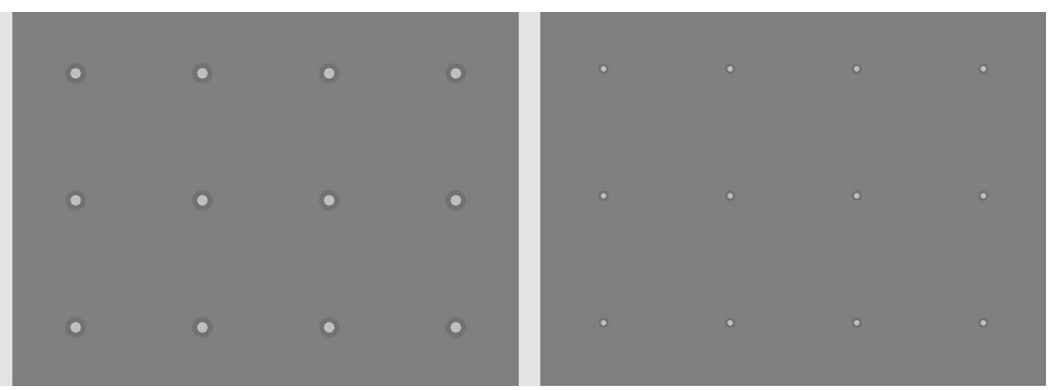

that correspond to the American Association for Pediatric Ophthalmology and Strabismus (AAPOS) recommended visual acuity screening levels for 3-, 4-, 5-, and 6-year-olds. Figure provided by Objective Acuity Ltd 


\section{OKN present}

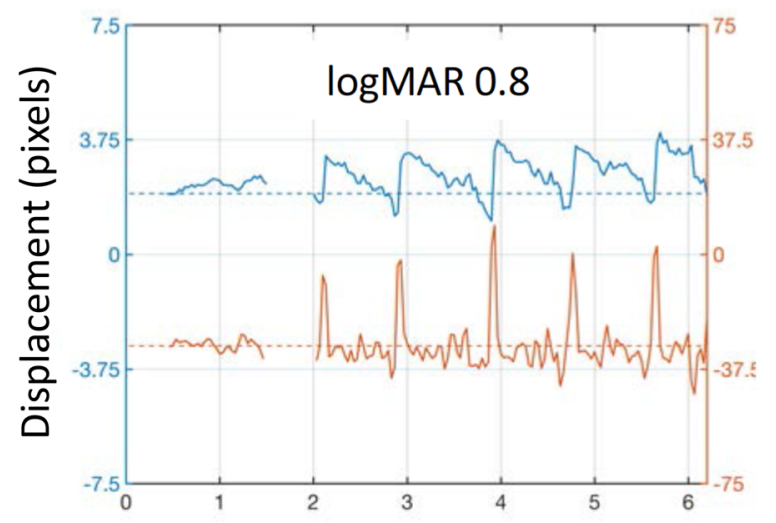

OKN absent

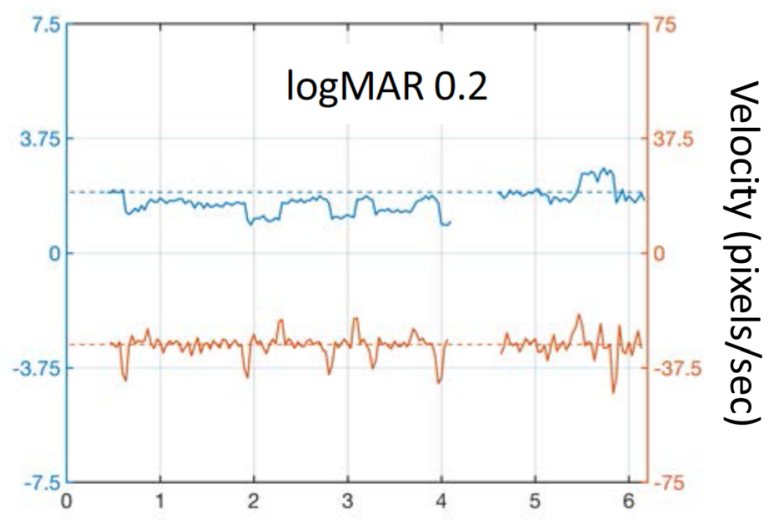

Time (sec)

Fig. $4 \mathrm{OKN}$ analysis software tracks position of the limbal edge, extracts horizontal eye velocity, and uses a machine learning algorithm to categorize velocity spike patterns as OKN present or absent. Figure provided by Objective Acuity Ltd

specificity of this approach for detecting decreased visual acuity in preschool children.

\section{Artificial Intelligence and Screening}

The promising role of artificial intelligence (AI) to enhance preschool vision screening is only now beginning to be investigated. Major drivers for this effort are the shortage of pediatric ophthalmologists, poor access to health screenings in underserved populations, and a clear appreciation of the benefit of early screening that leads to early interventions that can improve long-term outcomes. One such device has been developed by DIVE Medical that uses an eye tracker to provide a fast and objective measurement of visual acuity and fixation instability [23]. AI can be used to adapt the progression of test stimuli to each child's performance to minimize test time and $\mathrm{AI}$ parameterized algorithms and heuristics can optimize sensory, imaging, and eye movement data processing. Overall, the goal is to train the neural network models and to evaluate their diagnostic accuracy for amblyopia and strabismus compared with a gold standard comprehensive examination [23]. Another AI approach, which has yet to be explored for pediatric vision screening, is to collect symptom data by electronic child- or parent-report as the input for machine learning-based prediction models for amblyopia. This approach has worked well for diverse medical conditions in adults, including early detection of immunerelated adverse events [24], predicting cognitive decline [25], and the need for cataract surgery [26]. If accurate, AI could provide a low-cost, low-manpower, and accessible approach to preschool vision screening.

\section{ADVANCES IN AMBLYOPIA TREATMENTS}

There is solid evidence that initial amblyopia treatment should be refractive correction, which improves retinal image quality by correcting refractive errors with spectacles. With optical correction alone within 30 weeks, amblyopia resolved in about one-third of previously untreated amblyopic children [27, 28]. For those who do not resolve with refractive correction alone, other amblyopia treatments are required. Treatment are available that primarily target the monocular visual acuity deficit or that target the binocular dysfunction and suppression. 


\section{Novel Monocular Treatment Approaches}

The current standard-of-care focuses on targeting the monocular visual acuity deficit by forcing the amblyopic eye to actively work, and thereby promoting normalization of visual cortical function in response to visual input from the amblyopic eye. Standard-of-care monocular treatments with robust evidence from randomized clinical trials (RCTs) include patching, atropine, and Bangerter filters.

After stable visual acuity was achieved with spectacle wear, 3- to 8-year-old amblyopic children randomized to patching treatment improved an additional 0.2 to 0.4 logMAR (2-4 lines) than children who continued with spectacles alone $[29,30]$. More than $80 \%$ of the improvement with patching occurred within 6 weeks [30]. Treatment outcome was significantly better for children younger than 5 years than children older than 7 years [30, 31]. Nonetheless, even in children 7-17 years old, patching is significantly better than optical correction alone [32]. Two other monocular treatments, atropine penalization and Bangerter filters, have also been evaluated in RCTs (Table 1). Atropine penalization has been shown to be as effective as patching in treating both moderate and severe amblyopia among children aged 3-6 years [33, 34]. Bangerter filters are also effective in improving vision for moderate amblyopia [35-37]. Although the Bangerter group improved slightly less than the patching group, the Bangerter filters were associated with a lower treatment burden and are recommended as a reasonable option for moderate amblyopia [36].

The dose-response relationship for patching is not yet fully understood. One may assume that the longer hours of patching result in more vision improvement. Paradoxically, for moderate amblyopia, a prescribed patching dose of $2 \mathrm{~h}$ /day resulted in the same amount of visual acuity improvement as a prescribed patching dose of $6 \mathrm{~h}$ /day [38] and, for severe amblyopia, $6 \mathrm{~h}$ /day yielded similar results to $12 \mathrm{~h}$ /day [39]. However, these studies did not objectively monitor adherence with the prescribed patching regimens. The similar visual acuity outcomes may have been due to a lack of adherence with the higher prescribed doses, i.e., the two treatment groups may have actually received similar doses despite being prescribed different doses. If we want to understand the dose-response relationship of patching, and determine any other factors that may be involved in modulating the child's response to patching, we need to objectively monitor patching.

Table 1 Randomized clinical trials evaluating monocular treatments of amblyopia that include younger children who traditionally respond to patching

\begin{tabular}{|c|c|c|c|c|c|c|}
\hline Study & $\begin{array}{l}\text { Mean age, years } \\
\text { (range) }\end{array}$ & Monocular therapy & $\begin{array}{l}\text { Comparison } \\
\text { group }\end{array}$ & $\begin{array}{l}\text { VA } \\
\text { improved? }\end{array}$ & $\begin{array}{l}\text { VA improved } \\
\text { more? }\end{array}$ & $\begin{array}{l}\text { Mean VA } \\
\text { improvement }\end{array}$ \\
\hline $\begin{array}{l}\text { Wang et al. } \\
\text { [48] }\end{array}$ & $5.7(3-8)$ & $\begin{array}{l}\text { Intermittent } \\
\text { occlusion glasses }\end{array}$ & Patching & Yes & No & $\begin{array}{r}1.5 \text { lines in } \\
12 \text { weeks }\end{array}$ \\
\hline $\begin{array}{l}\text { Iwata et al. } \\
\text { [51] }\end{array}$ & $4.8(3-7)$ & Occlu-pad & Glasses & Yes & Yes & $\begin{array}{l}1.9 \text { lines in } \\
12 \text { weeks } \\
3.0 \text { lines in } \\
24 \text { weeks }\end{array}$ \\
\hline $\begin{array}{c}\text { PEDIG } \\
{[33]}\end{array}$ & $5.3(3-7)$ & Atropine & Patching & Yes & No & $\begin{array}{r}3.7 \text { lines in } \\
24 \text { weeks }\end{array}$ \\
\hline $\begin{array}{c}\text { PEDIG } \\
{[36]}\end{array}$ & $6.3(3-10)$ & Bangerter filter & Patching & Yes & No & $\begin{array}{l}1.9 \text { lines in } \\
24 \text { weeks }\end{array}$ \\
\hline
\end{tabular}




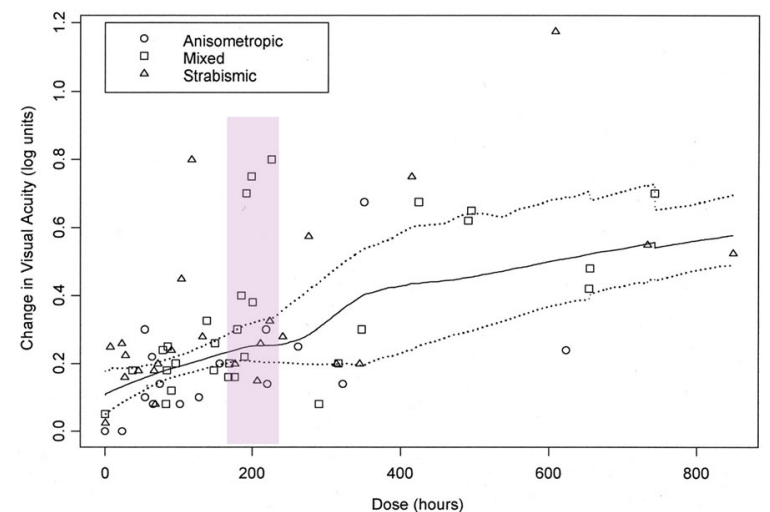

Fig. 5 The dose-response relationship for patching versus number of hours in the MOTAS study [30] Reprinted with permission from the author (Katherine Stewart); purple highlight added
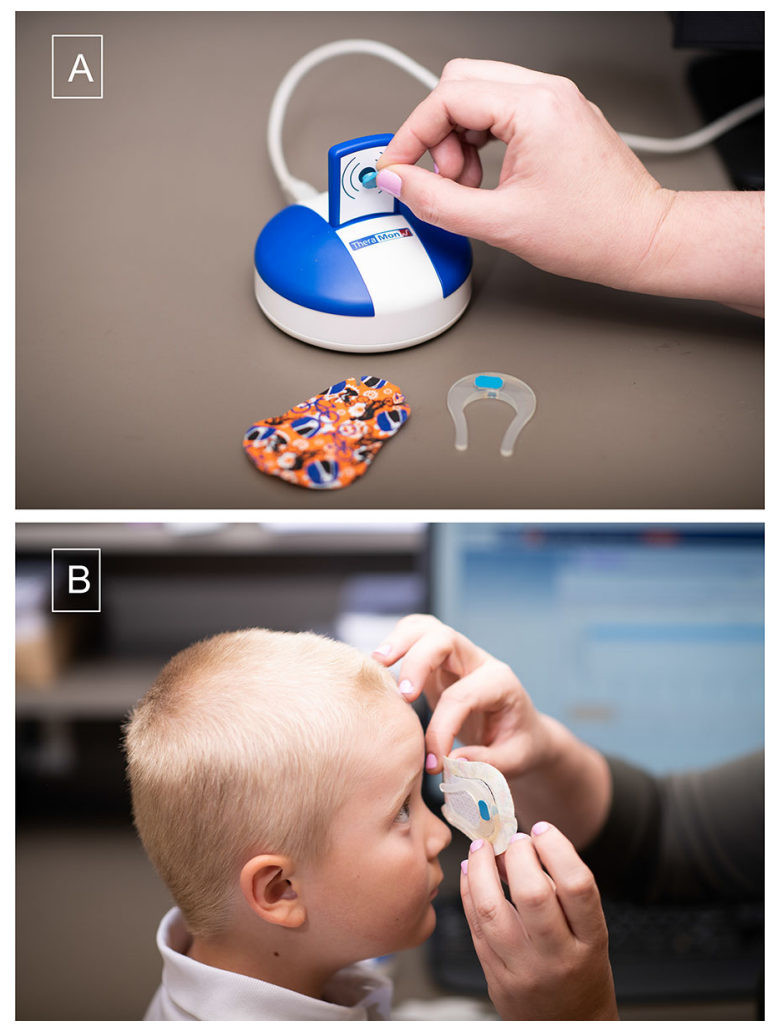

Fig. 6 The temperature-sensitive Theramon $^{\circledR}$ sensor is fit into a horseshoe shaped silicone Eye Patch Assistant (EPA) [47], which can then be placed on an adhesive eye patch, shown next to sensor reading device (a). Also shown is the EPA with a microsensor in place on the eyepatch, ready to place over the child's eye (b)
Only one patching RCT objectively monitored adherence, the Monitored Occlusion Treatment of Amblyopia Study (MOTAS). Researchers used an occlusion dose monitor (ODM) to track adherence with patching via two miniature electrocardiogram electrodes attached to the undersurface of the patch to detect skin contact [40]. The authors reported a positive dose-response relationship between the number of hours of patching and the amount of visual acuity improvement (Fig. 5) [30]. Surprisingly, even within this homogeneous cohort of amblyopic children aged 3-8 years with no prior treatment other than spectacles, individual differences in dose-response were large. With about 200 cumulative hours of patching (verified by an ODM; highlighted in Fig. 6), the visual acuity improvement range was wide, from 0.2 logMAR (2 lines) to $0.8 \log$ MAR (8 lines) [30]. These results suggest that poor adherence to prescribed patching regimens was not the only factor influencing visual acuity outcomes-other unidentified factors may contribute to these individual differences [41]. Other factors known to be related to adherence to patching include the parents' understanding of the treatment, stress, discomfort of patches, and the social stigma associated with patching [42].

Researchers from the UK [40, 43] and the Netherlands [44] have pioneered objective monitoring of patching with an ODM. However, the UK ODM is no longer available and the Netherlands ODM is not available in North America. In 2013, German colleagues introduced a temperature-sensitive microsensor (Theramon ${ }^{\circledR}$ ) for monitoring adherence to patching $[45,46]$. Advantages of the microsensor include its small size, waterproof coating, long battery life, and data storage capacity of up to 100 days. Shortcomings of the microsensor include that its small size makes it hard to hold and is easily lost, it is difficult to place on a patch consistently, and it is a swallow hazard due to its candy-like appearance. Despite the attractive advantages, shortcomings of the microsensor have limited its use in research and clinical practice $[45,46]$.

To decrease the likelihood that the microsensor will be lost or swallowed, and to 
facilitate consistent application of the microsensor to an adhesive patch, the Eye Patch Assistant (EPA) was recently designed [47]. The EPA, a horseshoe-shaped holder for the microsensor, is made of biocompatible silicone, and can be adhered to the inside of a regular size adhesive eye patch (Fig. 6). The EPA has a recessed opening so that the microsensor fits flush for positioning on the temple, and has an open side positioned toward the nose for comfortable spectacle wear [47]. Currently, the first RCT to use this EPA ODM to evaluate patching is being conducted by the Pediatric Eye Disease Investigator Group (ClinicalTrials.gov ID NCT04378790).

To offset the challenges of traditional patching treatment, researchers are evaluating new occlusion technology. Liquid crystal glasses provide a new monocular treatment-intermittent occlusion therapy (IO-therapy) - in which the spectacle lens that covers the fellow eye changes between opaque and transparent states every $30 \mathrm{~s}$ [48]. A recent RCT found that intermittent occlusion via IO-therapy glasses (Amblyz) for $4 \mathrm{~h} /$ day was as effective as patching $2 \mathrm{~h}$ /day in treating 3- to 7-year-old children with moderate amblyopia (Table 1) [48]. In a subsequent study, using the Theramon microsensor to monitor adherence with IOtherapy glasses, the authors reported similar adherence to patching [49]. An ongoing RCT (ClinicalTrials.gov ID NCT02767856) is further comparing intense and standard regimens of IO-therapy.

Another recently developed monocular treatment alternative for occlusion is the OccluPad [50]. By removing the polarizing film layer from the liquid crystal display screen of an iPad Air, the LCD display is visible only to the amblyopic eye with the aid of an exactly matched polarizing filter. Meanwhile, the fellow eye is given a neutral density filter to match the luminance seen by the amblyopic eye but, without a polarizing filter, the fellow eye is only able to see the white backlight of the display. As a result, images are selectively seen by the amblyopic eye even though the child views the tablet with both eyes. Although the authors called this treatment "dichoptic", the nature of this treatment is based on the monocular deficit approach, i.e., occlusion of the fellow eye. In a single-site RCT of children aged 3-7 years with anisometropic amblyopia and stable visual acuity in glasses, playing a game on the OccluPad 0.5-h/day twice per week led to significantly more visual acuity improvement than glasses alone (Table 1) [51].

Besides these individual treatment options, some RCTs have investigated various combinations of treatments and have reported an added benefit of the combination over patching alone, e.g., patching plus atropine for residual amblyopia [52] and patching plus monocular video games [53]. Other studies of combined treatments did not report an additional benefit, e.g., patching plus near activities [54], patching plus levodopa [55], and patching plus citalopram [56].

\section{Novel Binocular Treatment Approaches}

Many children do not achieve normal visual acuity, even after months or years of patching and atropine, and of those that do, up to half will regress [57]. Further, normal binocularity (i.e., stereoacuity) is rarely restored [57-60], even if normal visual acuity is attained, which may be because the eyes are not encouraged to work together during patching treatment. Over the last few decades there has been a paradigm shift in how the etiology of amblyopia is viewed. Rather than the centuries-old "monocular disorder" view, recent evidence points to amblyopia as a "binocular disorder". In animal models of amblyopia, interocular suppression is heightened in visual areas V1 and V2, and the severity of suppression is correlated with the behavioral sensory deficit [61, 62]. Further, interocular suppression in $\mathrm{V} 1$ is reduced when a gamma aminobutyric acid (GABA) antagonist is introduced [63]. In amblyopic humans, research shows that interocular suppression plays a major role in the etiology of amblyopia, and there is a strong relationship between severity of amblyopia and the severity of suppression [64-66]. Combined, these psychophysical and physiological data point to a structurally intact binocular visual system that is rendered 


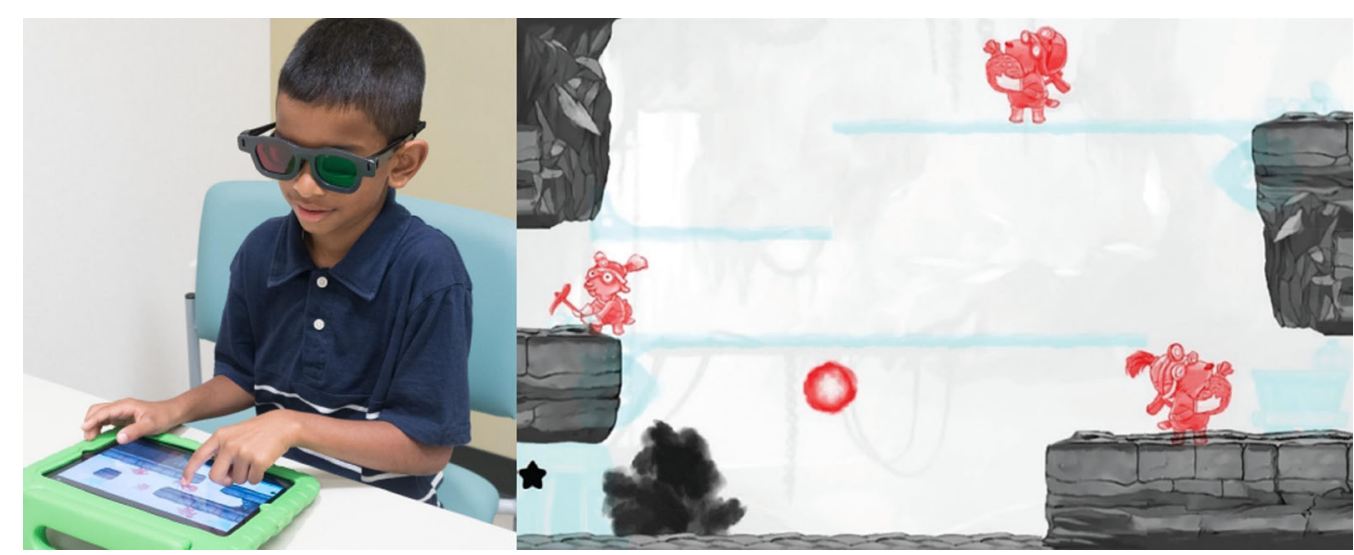

Fig. 7 A child wearing red-green anaglyphic glasses to play the contrast-rebalanced Dig Rush game for amblyopia treatment (left) and an example screen from the Dig Rush game (right) [69]. The amblyopic eye, viewing through a green filter, sees the high-contrast red elements of the game (miners and fireball) while the fellow eye, viewing through a red filter, sees the reduced contrast blue elements (gold nuggets and mining cart). Gray elements are seen by both eyes. Avoiding obstacles, the child must move the miners to retrieve the gold and fill the cart. Game levels progressively increase in difficulty

Table 2 Randomized clinical trials evaluating contrast-rebalanced binocular game treatment of amblyopia that include younger children who traditionally respond to patching

\begin{tabular}{|c|c|c|c|c|c|c|}
\hline Study & $\begin{array}{l}\text { Mean age, } \\
\text { years (range) }\end{array}$ & $\begin{array}{l}\text { Binocular } \\
\text { treatment }\end{array}$ & $\begin{array}{l}\text { Comparison } \\
\text { group }\end{array}$ & $\begin{array}{l}\text { VA } \\
\text { improved? }\end{array}$ & $\begin{array}{l}\text { VA } \\
\text { improved } \\
\text { more? }\end{array}$ & $\begin{array}{l}\text { Mean VA } \\
\text { improvement }\end{array}$ \\
\hline Xiao et al. [75] & $6.1(4-7)$ & Videos & Glasses & Yes & Yes & $\begin{array}{l}1.8 \text { lines in } \\
12 \text { weeks }\end{array}$ \\
\hline Holmes et al. [77] & $5.8(4-7)$ & Dig Rush & Glasses & Yes & Yes & $\begin{array}{l}1.1 \text { lines in } \\
4 \text { weeks }\end{array}$ \\
\hline Jost et al. [74] & $7.6(4-10)$ & $\begin{array}{c}\text { Dig Rush, } \\
\text { Monster } \\
\text { Burner }\end{array}$ & $\begin{array}{c}\text { Different } \\
\text { contrast } \\
\text { protocols }\end{array}$ & Yes & No & $\begin{array}{c}1.4 \text { lines in } \\
8 \text { weeks }\end{array}$ \\
\hline $\begin{array}{l}\text { Birch et al.; Kelly } \\
\text { et al. }[69,100]\end{array}$ & $6.8(4-10)$ & Dig Rush & Patch & Yes & Yes & $\begin{array}{c}1.8 \text { lines in } \\
4 \text { weeks }\end{array}$ \\
\hline Yao et al. [73] & $6.0(3-13)$ & Push-Pull & Patch & Yes & No & $\begin{array}{r}1.8 \text { lines in } \\
12 \text { weeks }\end{array}$ \\
\hline PEDIG [76] & $8.5(5-12)$ & Tetris & Patch & Yes & No & $\begin{array}{l}1.1 \text { lines in } \\
16 \text { weeks }\end{array}$ \\
\hline
\end{tabular}

functionally monocular in amblyopia due to active suppression.

Capitalizing on this recent shift in our understanding of the etiology of amblyopia, researchers have discovered that suppression can be reduced by rebalancing the signal between the two eyes, thereby allowing for binocular interaction [57, 65, 67]. This is achieved by decreasing the signal (i.e., decrease luminance or contrast) in the fellow eye while 
the signal to the amblyopic eye remains high $[64,65,67]$. Multiple labs have put this finding to use by creating binocular amblyopia treatments that alleviate amblyopic eye suppression using dichoptic games and movies presented on tablets, computer screens, and in virtual reality headsets (Fig. 7) [68-75]. While preliminary data show promising results, many of the binocular amblyopia treatments have yet to be rigorously tested in RCTs. In general, RCTs suggest that binocular treatments can be used effectively as a treatment for amblyopia in children in as little as $2-16$ weeks [69, 73-77]. Still, there is some debate in the literature about whether binocular amblyopia treatment works $[78,79]$. Studies with small or no improvements have been hindered by poor compliance, and by enrolling older children and adults who had abandoned amblyopia treatment after months or years of patching and atropine with intractable residual amblyopia [80-82]. Table 2 reports binocular treatment RCTs that included younger children who traditionally respond to patching treatment (less than 7 years of age). Although superiority was not found for some studies, the key finding is that amblyopic eye visual acuity significantly improved from baseline with binocular treatment in all of these RCTs. Regardless of whether binocular treatments are better than patching, there is strong evidence that binocular treatments are at least equal to patching and can be considered as an additional treatment option [79].

In the clinic, improving visual acuity is the main goal of amblyopia treatment, and once achieved, treatment is terminated. Yet, binocular deficits persist in almost half of those whose visual acuity deficit resolves [57, 59, 60]. Rather than just normal visual acuity, restoring binocularity is also an important treatment goal. There is preliminary evidence that binocular treatments may improve stereoacuity and interocular suppression as well as visual acuity [73, 74, 83, 84]. In addition, some researchers are using dichoptic methods to train stereopsis directly $[85,86]$. Promising results suggest the possibility of prolonging treatment after normal visual acuity has been achieved to include stereoacuity training. Poor stereoacuity is related to increased risk of recurrent misalignment following strabismus surgery [60, 87]; therefore the addition of stereoacuity training may help maintain alignment in those with strabismus. Binocular dysfunction is also implicated in impaired motor ability and is associated with an increased risk of injury [88-93]. Improving stereoacuity with binocular treatment could help improve motor ability [83], and in turn, reduce injuries, and improve self-esteem and quality of life [93-96]. Improved vision and binocularity may also open up more doors career-wise, as vision requirements exist for certain jobs such as aviation, law enforcement, and surgery [97-99].

Some may question whether high-tech, alternative treatments will cost more than traditional treatments for amblyopia, either to third-party payers or the families of children with amblyopia, and whether they will be easily accessible. While the new technologies may initially cost more or may not be covered by third-party payers, over time and with demand, direct costs of the treatment are likely to decrease and eventually be accepted as a treatment option if proven effective. Indirect costs may also be less than anticipated. There is evidence that visual acuity improvements with binocular treatment occur faster than patching - at least in the beginning-with gains of about 1-2 lines occurring in just $4-8$ weeks rather than with 4-6 months of patching $[30,36,48,69,75,76,100]$. Further, visual acuity of $20 / 32$ or better was achieved within 4 weeks in $35-39 \%$ of children randomized to binocular treatment, but only in $7-8 \%$ of children randomized to patching $[69,100]$. These findings suggest that visual acuity gains may be faster in the short term with binocular treatment than patching. If true, this could reduce the cost of visits, travel to appointments, and time off work for parents. Clinicians may choose to loan or rent the devices rather than requiring the families to purchase these items, or to provide children with treatment software that can be used on devices the family already owns, further reducing costs and increasing accessibility. Initial studies of binocular treatment were completed in the lab. Now, treatments can be completed at home. With improvements in gaming and movie content, 
compliance has the potential to be much better than patching. As binocular treatments evolve and become commercially available, the cost for a typical child patching for 6 months may be equivalent to the cost of a child undergoing binocular treatment for 1-2 months.

Whether binocular treatment can cure amblyopia remains to be determined. So far, there have only been short-term proof-of-principle studies with games designed to last only about $4-8$ weeks that may be too simple to maintain a child's interest for long, especially older children. Further, current treatments may not be able to treat those with severe amblyopia as they are unlikely to see all of the game or movie elements. Lastly, younger children may not be able to understand or play the games, or may be uninterested in watching the movies. Fortunately, many of these issues are continuing to be addressed as research continues.

\section{WHAT'S ON THE HORIZON?}

Recent research has shown that amblyopia not only impacts vision of the affected eye; functional consequences include deficits in the stronger, fellow eye, slow reading, impaired motor skills, and low self-esteem and quality of life (see "Box")—all issues that can streamline into a child's everyday life, and persist into adulthood [88, 93-96, 101-107]. Therefore, it is imperative that this condition be diagnosed and treated as early as possible. Recent advances in screening offer hope for early detection that can be used in a broad range of settings. Similar to the interchangeability of patching, atropine, and Bangerter filters, the new monocular and binocular advances in amblyopia treatment provide alternatives that can be used alone or in combination with these standard-of-care treatments. A larger repertoire of treatment options will help improve compliance and vision outcomes.

\section{FUNCTIONAL CONSEQUENCES OF AMBLYOPIA}

\section{Fellow Eye Deficits}

- Children with amblyopia have impaired motion-defined form perception and global motion perception in their fellow eye [101].

- Fixation instability is present in the fellow eye of children with amblyopia [104].

\section{Slow Reading}

- Children with amblyopia read 25\% slower than their peers [102].

- Ocular motor dysfunction associated with amblyopia (i.e., increased forward saccades, fixation instability) may be a cause of slow reading [103].

\section{Impaired Motor Skills}

- Children with amblyopia have impaired motor skills (e.g., manual dexterity, aiming, catching, balance, and walking) [88-92, 106].

- Children with amblyopia are $25 \%$ slower at transferring answers to a multiple-choice answer sheet [105].

- Motor impairments are related to early onset, strabismus, reduced binocularity, and ocular motor dysfunction [88].

\section{Self-Perception and Quality of Life}

- Amblyopia affects children's self-perception, especially of physical competence and peer acceptance [94-96].

- Children with amblyopia and their parents have reduced quality of life scores [107].

\section{ACKNOWLEDGEMENTS}

Funding. This study, including the journal's Rapid Service Fees, was supported in part by 
funding from the National Eye Institute, including EY022313 (Eileen E Birch), EY027633 (Eileen E Birch), EY028224 (Krista R Kelly), and the Canadian Institutes of Health Research 390283 (Eileen E Birch).

Prior Presentation. The information in this article was presented, in part, as an Invited Talk entitled "Recent Advances in Screening and Treatment for Amblyopia" in a Symposium at the 2021 Virtual Annual Meeting of the Association for Research in Vision and Ophthalmology entitled "Childhood Vision Disorders: What is on the Horizon?"

Authorship. All named authors meet the International Committee of Medical Journal Editors criteria for authorship of this article. Take responsibility for the integrity of the work as a whole, and have given their approval for this version to be published.

Authorship Contributions. Conceptualization (Eileen E Birch); Literature review (Eileen E Birch, Krista R Kelly, Jingyun Wang), Writingoriginal draft preparation (Eileen E Birch, Krista R Kelly, Jingyun Wang); Writing-review and editing (Eileen E Birch, Krista R Kelly, Jingyun Wang). All authors read and approved the final manuscript.

Disclosures. Eileen E Birch is a Consultant for Objective Acuity Ltd. Jingyun Wang is a member of the Advisory Board for Percept Corporation. Krista R Kelly declares that she has no conflict of interest.

Compliance with Ethics Guidelines. This article is based on previously conducted studies and does not contain any new studies with human participants or animals performed by any of the authors.

Data Availability. Data sharing is not applicable to this article as no datasets were generated or analyzed during the current study.

Open Access. This article is licensed under a Creative Commons Attribution-NonCommercial 4.0 International License, which permits any non-commercial use, sharing, adaptation, distribution and reproduction in any medium or format, as long as you give appropriate credit to the original author(s) and the source, provide a link to the Creative Commons licence, and indicate if changes were made. The images or other third party material in this article are included in the article's Creative Commons licence, unless indicated otherwise in a credit line to the material. If material is not included in the article's Creative Commons licence and your intended use is not permitted by statutory regulation or exceeds the permitted use, you will need to obtain permission directly from the copyright holder. To view a copy of this licence, visit http://creativecommons.org/licenses/by$\mathrm{nc} / 4.0 /$.

\section{REFERENCES}

1. Friedman DS, Repka MX, Katz J, et al. Prevalence of amblyopia and strabismus in White and African American children aged 6 through 71 months the Baltimore Pediatric Eye Disease Study. Ophthalmology. 2009;116(2128-34):e1-2.

2. Giordano L, Friedman DS, Repka MX, et al. Prevalence of refractive error among preschool children in an urban population: the Baltimore Pediatric Eye Disease Study. Ophthalmology. 2009;116:739-46 e1-4.

3. Multi-Ethnic Pediatric Eye Disease Study. Prevalence of amblyopia and strabismus in African American and Hispanic children ages 6 to 72 months the Multi-Ethnic Pediatric Eye Disease Study. Ophthalmology. 2008;115:1229-36 e1.

4. Mema SC, McIntyre L, Musto R. Childhood vision screening in Canada: public health evidence and practice. Can J Public Health. 2012;103:40-5.

5. Sloot F, Hoeve HL, de Kroon ML, et al. Inventory of current EU paediatric vision and hearing screening programmes. J Med Screen. 2015;22:55-64.

6. Donahue SP, Ruben JB. US Preventive Services Task Force vision screening recommendations. Pediatrics. 2011;127:569-70.

7. British and Irish Orthoptic Society. Vision screening. 2021. https://www.orthoptics.org.uk/policyand-campaigns/vision-screening/. Accessed 23 June 2021 
8. Williams C, Northstone K, Howard M, et al. Prevalence and risk factors for common vision problems in children: data from the ALSPAC study. $\mathrm{Br} J$ Ophthalmol. 2008;92:959-64.

9. Williams C, Harrad R. Amblyopia: contemporary clinical issues. Strabismus. 2006;14:43-50.

10. Williams C, Harrad RA, Harvey I, Sparrow JM, ALSPAC Study Team. Screening for amblyopia in preschool children: results of a population-based, randomised controlled trial. Ophthalmic Epidemiol. 2001;8:279-95.

11. Wall TC, Marsh-Tootle W, Evans HH, Fargason CA, Ashworth CS, Hardin JM. Compliance with visionscreening guidelines among a national sample of pediatricians. Ambul Pediatr. 2002;2:449-55.

12. Wasserman RC, Croft CA, Brotherton SE. Preschool vision screening in pediatric practice: a study from the Pediatric Research in Office Settings (PROS) Network. Pediatrics. 1992;89:834-8.

13. Kemper AR, Clark SJ. Preschool vision screening in pediatric practices. Clin Pediatr. 2006;45:263-6.

14. Marsh-Tootle WL, Wall TC, Tootle JS, Person SD, Kristofco RE. Quantitative pediatric vision screening in primary care settings in Alabama. Optom Vis Sci. 2008;85:849-56.

15. Kemper AR, Wallace DK, Patel N, Crews JE. Preschool vision testing by health providers in the United States: findings from the 2006-2007 Medical Expenditure Panel Survey. J AAPOS. 2011;15:480-3.

16. Arnold RW. Amblyopia risk factor prevalence. J Pediatr Ophthalmol Strab. 2013;50:213-7.

17. Holmes JM. When to screen for amblyopia. J AAPOS. 2020;24:65-6.

18. Jost RM, Yanni SE, Beauchamp CL, et al. Beyond screening for risk factors: objective detection of strabismus and amblyopia. JAMA Ophthalmol. 2014;132:814-20.

19. Jost RM, Stager D Jr, Dao L, Katz S, McDonald R, Birch EE. High specificity of the pediatric vision scanner in a private pediatric primary care setting. J AAPOS. 2015;19:521-5.

20. Turuwhenua J, Yu TY, Mazharullah Z, Thompson B. A method for detecting optokinetic nystagmus based on the optic flow of the limbus. Vis Res. 2014;103:75-82.

21. Sangi M, Thompson B, Turuwhenua J. An optokinetic nystagmus detection method for use with young children. IEEE J Transl Eng Health Med. 2015;3:1600110.
22. Harris PA, Garner T, Sangi M, Guo P, Turuwhenua J, Thompson B. Visual acuity assessment in adults using optokinetic nystagmus. Invest Ophthalmol Vis Sci. 2019;60:5907.

23. Pueyo V, Perez-Roche T, Prieto E, et al. Development of a system based on artificial intelligence to identify visual problems in children: study protocol of the TrackAI project. BMJ Open. 2020;10: e033139.

24. Iivanainen S, Ekstrom J, Virtanen H, Kataja VV, Koivunen JP. Electronic patient-reported outcomes and machine learning in predicting immune-related adverse events of immune checkpoint inhibitor therapies. BMC Med Inform Decis Mak. 2021;21:205.

25. Pereiro AX, Valladares-Rodriguez S, Felpete A, et al. Relevance of complaint severity in predicting the progression of subjective cognitive decline and mild cognitive impairment: a machine learning approach. J Alzheimers Dis. 2021;82:1229-42.

26. Wang W, Han X, Zhang J, et al. Predicting the 10-year risk of cataract surgery using machine learning techniques on questionnaire data: findings from the 45 and up study. Br J Ophthalmol. 2021. https://doi.org/10.1136/bjophthalmol-2020318609.

27. Pediatric Eye Disease Investigator Group. Treatment of anisometropic amblyopia in children with refractive correction. Ophthalmology. 2006;113: 895-903.

28. Pediatric Eye Disease Investigator Group. Optical treatment of strabismic and combined strabismicanisometropic amblyopia. Ophthalmology. 2012;119:150-8.

29. Pediatric Eye Disease Investigator Group. A randomized trial to evaluate two hours of daily patching for amblyopia in children. Ophthalmology. 2006;113:904-12.

30. Stewart CE, Moseley MJ, Stephens DA, Fielder AR. Treatment dose-response in amblyopia therapy: The Monitored Occlusion Treatment of Amblyopia Study (MOTAS). Invest Ophthalmol Vis Sci. 2004;45:3048-54.

31. Holmes JM, Lazar EL, Melia BM, et al. Effect of age on response to amblyopia treatment in children. Arch Ophthalmol. 2011;129:1451-7.

32. Pediatric Eye Disease Investigator Group. Randomized trial of treatment of amblyopia in children aged 7 to 17 years. Arch Ophthalmol. 2005;123: 437-47. 
33. Pediatric Eye Disease Investigator Group. A randomized trial of atropine vs. patching for treatment of moderate amblyopia in children. Arch Ophthalmol. 2002;120:268-78.

34. Pediatric Eye Disease Investigator Group. Treatment of severe amblyopia with weekend atropine: results from 2 randomized clinical trials. J AAPOS. 2009;13: 258-63.

35. Agervi P, Kugelberg U, Kugelberg M, Simonsson G, Fornander M, Zetterstrom C. Treatment of anisometropic amblyopia with spectacles or in combination with translucent Bangerter filters. Ophthalmology. 2009;116:1475-80.

36. Pediatric Eye Disease Investigator Group. A randomized trial comparing Bangerter filters and patching for the treatment of moderate amblyopia in children. Ophthalmology. 2010;117:998-1004 e6.

37. Agervi P, Kugelberg U, Kugelberg M, Zetterstrom C. Two-year follow-up of a randomized trial of spectacles alone or combined with Bangerter filters for treating anisometropic amblyopia. Acta Ophthalmol. 2013;91:71-7.

38. Pediatric Eye Disease Investigator Group. A randomized trial of patching regimens for treatment of moderate amblyopia in children. Arch Ophthalmol. 2003;121:603-11.

39. Pediatric Eye Disease Investigator Group. A randomized trial of prescribed patching regimens for treatment of severe amblyopia in children. Ophthalmology. 2003;110:2075-87.

40. Fielder AR, Irwin M, Auld R, Cocker KD, Jones HS, Moseley MJ. Compliance in amblyopia therapy: objective monitoring of occlusion. Br J Ophthalmol. 1995;79:585-9.

41. Stewart CE, Fielder AR, Stephens DA, Moseley MJ. Treatment of unilateral amblyopia: factors influencing visual outcome. Invest Ophthalmol Vis Sci. 2005;46:3152-60.

42. Wang J. Compliance and patching and atropine amblyopia treatments. Vis Res. 2015;114:31-40.

43. Stewart CE, Fielder AR, Stephens DA, Moseley MJ. Design of the Monitored Occlusion Treatment of Amblyopia Study (MOTAS). Br J Ophthalmol. 2002;86:915-9.

44. Chopovska Y, Loudon SE, Cirina L, et al. Electronic recording of occlusion treatment for amblyopia: potential of the new technology. Graefes Arch Clin Exp Ophthalmol. 2005;243:539-44.
45. Januschowski K, Bechtold TE, Schott TC, et al. Measuring wearing times of glasses and ocular patches using a thermosensor device from orthodontics. Acta Ophthalmol. 2013;91:e635-40.

46. Schramm C, Abaza A, Blumenstock G, et al. Limitations of the TheraMon-microsensor in monitoring occlusion therapy. Acta Ophthalmol. 2016;94: e753-6.

47. Wang J, Xu H, De La Cruz B, et al. Improved monitoring of adherence with patching treatment using a microsensor and eye patch assistant. J AAPOS. 2020;24(96):e1-7.

48. Wang J, Neely DE, Galli J, et al. A pilot randomized clinical trial of intermittent occlusion therapy liquid crystal glasses versus traditional patching for treatment of moderate unilateral amblyopia. J AAPOS. 2016;20:326-31.

49. Wang J, Jin J, Malik A, et al. Feasibility of monitoring compliance with intermittent occlusion therapy glasses for amblyopia treatment. J AAPOS. 2019;23:205:e1-205.e5.

50. Handa T, Ishikawa H, Shoji N, et al. Modified iPad for treatment of amblyopia: a preliminary study. J AAPOS. 2015;19:552-4.

51. Iwata $Y$, Handa T, Ishikawa H, Goseki T, Shoji N. Comparison between amblyopia treatment with glasses only and combination of glasses and opentype binocular "Occlu-Pad" device. Biomed Res Int. 2018;2018:2459696.

52. Pediatric Eye Disease Investigator Group. Randomized trial to evaluate combined patching and atropine for residual amblyopia. Arch Ophthalmol. 2011;129:960-2.

53. Singh A, Sharma P, Saxena R. Evaluation of the role of monocular video game play as an adjuvant to occlusion therapy in the management of anisometropic amblyopia. J Pediatr Ophthalmol Strab. 2017;54:244-9.

54. Pediatric Eye Disease Investigator Group. A randomized trial of near versus distance activities while patching for amblyopia in children aged 3 to less than 7 years. Ophthalmology. 2008;115:2071-8.

55. Pediatric Eye Disease Investigator Group. A randomized trial of levodopa as treatment for residual amblyopia in older children. Ophthalmology. 2015;122:874-81.

56. Lagas AK, Black JM, Russell BR, Kydd RR, Thompson B. The effect of combined patching and citalopram on vsual acuity in adults with amblyopia: a randomized, crossover, placebo-controlled trial. Neural Plast. 2019;2019:5857243. 
57. Birch EE. Amblyopia and binocular vision. Prog Retin Eye Res. 2013;33:67-84.

58. Stewart CE, Wallace MP, Stephens DA, Fielder AR, Moseley MJ. The effect of amblyopia treatment on stereoacuity. J AAPOS. 2013;17:166-73.

59. Wallace DK, Lazar EL, Melia M, et al. Steroacuity in children with anisometropic amblyopia. J AAPOS. 2011;15:455-61.

60. Birch EE, Wang J. Stereoacuity outcomes after treatment of infantile and accommodative esotropia. Optom Vis Sci. 2009;86:647-52.

61. Bi H, Zhang B, Tao X, Harwerth RS, Smith EL, Chino YM. Neuronal responses in visual area V2 (V2) of macaque monkeys with strabismic amblyopia. Cereb Cortex. 2011;21:2033-45.

62. Tao X, Zhang B, Shen G, et al. Early monocular defocus disrupts the normal development of receptive-field structure in V2 neurons of macaque monkeys. J Neurosci. 2014;34:13840-54.

63. Sengpiel F, Vorobyov V. Intracortical origins of interocular suppression in the visual cortex. J Neurosci. 2005;25:6394-400.

64. Birch EE, Morale SE, Jost RM, et al. Assessing suppression in amblyopic children with a dichoptic eye chart. Invest Ophalmol Vis Sci. 2016;57:5649-54.

65. Hess RF, Thompson B. Amblyopia and the binocular approach to its therapy. Vis Res. 2015;114:4-16.

66. Mansouri B, Thompson B, Hess RF. Measurement of suprathreshold binocular interactions in amblyopia. Vis Res. 2008;48:2775-84.

67. Levi DM. Rethinking amblyopia 2020. Vis Res. 2020;176:118-29.

68. Birch EE, Jost RM, De La Cruz A, et al. Binocular amblyopia treatment with contrast-rebalanced movies. J AAPOS. 2019;23:160.E1-160.E5-7. https://doi.org/10.1016/j.jaapos.2019.02.007.

69. Kelly KR, Jost RM, Dao L, Beauchamp CL, Leffler JN, Birch EE. Binocular iPad game vs patching for treatment of amblyopia in children: a randomized clinical trial. JAMA Ophthalmol. 2016;134:1402-8.

70. Žiak P, Holm A, Halička J, Mojžiš P, Piñero DP. Amblyopia treatment of adults with dichoptic training using the virtual reality oculus rift head mounted display: preliminary results. BMC Ophthalmol. 2017;17:105.

71. Xiao S, Gaier ED, Wu HC, et al. Digital therapeutic improves visual acuity and encourages high adherence in amblyopic children in open-label pilot study. J AAPOS. 2021;25(87):e1-6.

72. Herbison N, MacKeith D, Vivian A, et al. Randomised controlled trial of video clips and interactive games to improve vision in children with amblyopia using the I-BiT system. Br J Ophthalmol. 2016;100:1511-6.

73. Yao J, Moon HW, Qu X. Binocular game versus parttime patching for treatment of anisometropic amblyopia in Chinese children: a randomised clinical trial. Br J Ophthalmol. 2020;104:369-75.

74. Jost RM, Kelly KR, Hunter JS, et al. A randomized clinical trial of contrast increment protocols for binocular amblyopia treatment. J AAPOS. 2020;24(282):e1-7.

75. Xaio S, Angjeli E, Wu HC, et al. Randomized controlled trial of a dichoptic digitial therapeutic for amblyopia. Ophthamology. 2021. (In press).

76. Pediatric Eye Disease Investigator Group. Effect of a binocular iPad game vs part-time patching in children aged 5 to 12 years with amblyopia. JAMA Ophthalmol. 2016;134:1391-400.

77. Holmes J, Manny R, Kraker R, et al. A randomized trial of binocular treatment for amblyopia in 4-6year-olds. Abstract, Paper presented at the 2020 Annual Meeting of the American Academy of Ophthalmology.

78. Pineles SL, Aakalu VK, Hutchinson AK, et al. Binocular treatment of amblyopia: a report by the American Academy of Ophthalmology. Ophthalmology. 2020;127:261-72.

79. Brin TA, Chow A, Carter C, Oremus M, Bobier W, Thompson B. Efficacy of vision-based treatments for children and teens with amblyopia: a systematic review and meta-analysis of randomised controlled trials. BMJ Open Ophthalmol. 2021;6: e000657.

80. Gao TY, Guo CX, Babu RJ, et al. Effectiveness of a binocular video game vs placebo video game for improving visual functions in older children, teenagers, and adults with amblyopia: a randomized clinical trial. JAMA Ophthalmol. 2018;136: 172-181.

81. Elhusseiny AM, Bishop K, Staffa SJ, Zurakowski D, Hunter DG, Mantagos IS. Virtual reality prototype for binocular therapy in older children and adults with amblyopia. J AAPOS. 2021. https://doi.org/10. 1016/j.jaapos.2021.03.008.

82. Pediatric Eye Disease Investigator Group. A randomized trial of a binocular iPad game versus parttime patching in children aged 13 to 16 years with amblyopia. Am J Ophthalmol. 2018;186:104-15. 
83. Webber A, Wood JM, Thompson B. Fine motor skills of children with amblyopia improve following binocular treatment. Invest Opthalmol Vis Sci. 2016;57:4713-20.

84. Kelly KR, Jost RM, Wang Y-Z, et al. Improved binocular outcomes following binocular treatment for childhood amblyopia. Invest Ophalmol Vis Sci. 2018;59:1221-8.

85. Vedamurthy I, Knill DC, Huang SJ, et al. Recovering stereo vision by squashing virtual bugs in a virtual reality environment. Philos Trans $\mathrm{R}$ Soc $\mathrm{B}$. 2016;371:20150264.

86. Godinez A, Martin-Gonzalez S, Ibarrondo O, Levi DM. Scaffolding depth cues and perceptual learning in VR to train stereovision: a proof of concept pilot study. Sci Rep. 2021;11:10129.

87. Birch EE, Stager DR, Berry P, Leffler JN. Stereopsis and long-term stability of alignment in esotropia. J AAPOS. 2004;8:146-50.

88. Kelly KR, Morale SE, Beauchamp CL, Dao L, Luu BA, Birch EE. Factors associated with impaired motor skills in strabismic and anisometropic children. Invest Ophalmol Vis Sci. 2020;61:43.

89. Webber A. The functional impact of amblyopia. Clin Expl Optom. 2018;101:443-50.

90. O'Connor AR, Birch EE, Anderson S, Draper H. The functional significance of stereopsis. Invest Ophalmol Vis Sci. 2010;51:2019-23.

91. Grant S, Suttle C, Melmoth DR, Conway ML, Sloper JJ. Age- and stereovision-dependent eye-hand coordination deficits in children with amblyopia and abnormal binocularity. Invest Ophalmol Vis Sci. 2014;55:5687-701.

92. Niechwiej-Szwedo E, Goltz HC, Colpa L, Chandrakumar M, Wong AMF. Effects of reduced acuity and stereo acuity on saccades and reaching movements in adults with amblyopia and strabismus. Invest Ophthalmol Vis Sci. 2017;58:914-21.

93. Pineles SL, Repka MX, Yu F, Lum F. Risk of musculoskeletal injuries, fractures, and falls in medicare beneficiaries with disorders of binocular vision. JAMA Ophthalmol. 2016;133:60-5.

94. Birch EE, Castañeda YS, Cheng-Patel CS, et al. Selfperception of school-aged children with amblyopia and its association with reading speed and motor skills. JAMA Ophthalmol. 2019;137:167-73.

95. Webber A, Wood JM, Gole GA, Brown B. Effect of amblyopia on self-esteem in children. Optom Vis Sci. 2008;85:1074-81.
96. Birch EE, Castañeda YS, Cheng-Patel CS, et al. Selfperception in children aged 3 to 7 years with amblyopia and its association with deficits in vision and fine motor skills. JAMA Ophthalmol. 2019;137: 499-506.

97. Department of the Air Force. Medical examinations and standards. Department of the Air Force; 2020.

98. University of California Los Angeles. Police officer selection standards. https://www.police.ucla.edu/ employment/police-officer-selection-standards. Accessed 10 July 2021.

99. O'Connor M. Turning a blind eye: physical standards for surgeons. J Law Med. 2009;16:614-24.

100. Birch EE, Jost RM, Kelly KR, Leffler JN, Dao L, Beauchamp CL. Baseline and clinical factors associated with response to amblyopia treatment in a randomized clinical trial. Optom Vis Sci. 2020;97: $316-23$.

101. Birch EE, Kelly KR, Giaschi DE. Fellow eye deficits in amblyopia. J Binocul Vis Ocul Motil. 2019;69: 116-125.

102. Kelly KR, Jost RM, De La Cruz A, Birch EE. Amblyopic children read more slowly than controls under natural, binocular reading conditions. J AAPOS. 2015;19:515-20.

103. Kelly KR, Jost RM, De La Cruz A, et al. Slow reading in children with anisometropic amblyopia is associated with fixation instability and increased saccades. J AAPOS. 2017;21:447-51.

104. Kelly KR, Cheng-Patel CS, Jost RM, Wang Y-ZZ, Birch EE. Fixation instability during binocular viewing in anisometropic and strabismic children. Exp Eye Res. 2018;183:29-37.

105. Kelly KR, Jost RM, De La Cruz A, Birch EE. Multiplechoice answer form completion time in children with amblyopia and strabismus. JAMA Ophthalmol. 2018;136:938-41.

106. Webber A, Wood JM, Gole GA, Brown B. The effect of amblyopia on fine motor skills in children. Invest Ophthalmol Vis Sci. 2008;49:594-603.

107. Hatt SR, Leske DA, Castaneda YS, et al. Understanding the impact of residual amblyopia on functional vision and eye-related quality of life using the PedEyeQ. Am J Ophthalmol. 2020;218: 173-81. 